\title{
Trifunctional squaramide catalyst for efficient enantioselective Henry reaction activation
}

\author{
Juan V. Alegre-Requena, ${ }^{a}$ Eugenia Marqués-López ${ }^{\mathrm{a}}$ and Raquel P. Herrera ${ }^{\text {a* }}$ \\ a Laboratorio de Organocatálisis Asimétrica. Departamento de Química Orgánica. Instituto de Síntesis Química y \\ Catálisis Homogénea (ISQCH) CSIC-Universidad de Zaragoza. C/ Pedro Cerbuna 12, 50009 Zaragoza (Spain). E-mail: \\ raquelph@unizar.es
}

\begin{abstract}
A new class of trifunctional squaramide catalyst acting by mean of multiple interactions has been found in the study of the Henry reaction. Enantiomerically enriched nitroaldol products were obtained in good yields and high enantioselectivities under mild conditions using one of the smallest amount of organocatalyst reported so far for this reaction $(0.25 \mathrm{~mol} \%)$.
\end{abstract}

The catalyst was able to generate hydrogen bonding and anion- $\pi /$ hydrogen- $\pi$ interactions with the substrates, responsible of the improvement in the reactivity and the enantioselectivity of this process. Computational calculations support a mechanistic hypothesis based on an anion- $\pi$ effect, being this the first example reported in asymmetric catalysis.

Keywords: aldehyde; organocatalysis; Henry; nitroalkanes; squaramide; trifunctional.

\section{Introduction}

Multifunctional scaffolds have received special attention in the last decade, with the increasing interest for the synthesis of more complex catalytic systems with a high organization grade and a multidentate activation, to offer a cooperative effect resembling the role of enzymes. ${ }^{[1,2]}$ These structures could facilitate the formation of cooperative noncovalent interactions in a synergic way and thereby significantly improve their catalytic activity. This would overcome the drawback of high catalyst loading that commonly are used in organocatalysis, which is still a great challenge. ${ }^{[3]}$ These studies have focused on hydrogen bonding, electrostatics effects, $\pi-\pi$, cation- $\pi$, hydrophobic and Van der Waals forces. All these interactions are believed to be involved in stabilizing the transition states by lowering the energetic barrier with a remarkable increase in the rate of the reaction. These binding could also be responsible of the improvement in the stereoselectivity of the process by differentially stabilizing the diastereomeric pathways created in the transition state between the catalyst and the reacting components. Additionally, non-covalent interactions operating in a synergic way can afford the conformational restriction required to induce high enantioselectivity.

The reaction between an in situ generated nitronate species and a carbonyl compound, known as Henry (nitroaldol) reaction, ${ }^{[4]}$ is an important carbon-carbon bond-forming method in organic synthesis. ${ }^{[5]}$ This process represents a powerful and useful tool for the synthesis of valuable $\beta$-nitroalcohols providing, after further transformations of the versatile nitro group, efficient access to interesting and highly functionalized intermediates, like $\beta$-aminoalcohols and $\alpha$-hydroxy carboxylic acids. ${ }^{[6,7]}$ The Henry reaction may be promoted under many different conditions and using diverse catalytic systems providing from good-to-excellent enantioselectivities. ${ }^{[8,9]}$ In fact, many efforts have been invested for improving this method, and different kinds of organocatalysts have been explored in order to increase the pioneering results reported by Nájera and co-workers in 1994. ${ }^{[10]}$

Therefore, the development of new asymmetric Henry strategies is still important to address the construction of interesting building blocks as a crucial step in total synthesis (Figure 1). 


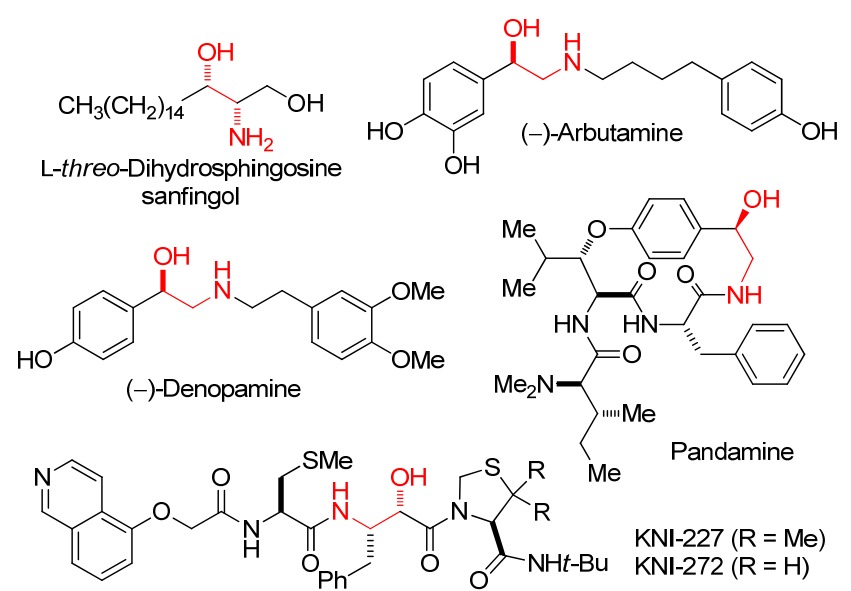

Figure 1. Biologically active compounds bearing a $\beta$ aminoalcohol motif.

Herein, we report a new class of trifunctional squaramide catalysts acting through multidentate activation, which efficiently catalyzes the asymmetric Henry reaction with high yields and high enantioselectivities (up to $94 \%$ ee). A low catalyst loading is required, routinely $2 \mathrm{~mol} \%$, and this can even be decreased to as low as $0.25 \mathrm{~mol} \%$ without detriment of the enantioselectivity. Interestingly, this is one of the lowest loading used so far in organocatalysis for this reaction. Moreover, this is the first reported example of a reaction using squaramides where an anion- $\pi$ interaction and an $\mathrm{H}-\pi$ interaction have been found in the transition state (TS) and could justify the efficiency of the used catalyst. To the best of our knowledge, this kind of activation has not been explored so far in asymmetric catalysis, and therefore this work could represent a pivotal contribution in this field. ${ }^{[11,12]}$

In this respect, many reactions are efficiently promoted using multifunctional catalysts, where nucleophile and electrophile are simultaneously coordinated to the different functional groups present in the catalyst structure. ${ }^{[13]}$ In the case of the Henry reaction, both components could be efficiently approached in the TS following a bifunctional coordination and represents an attractive model to explore this concept. Based on previous developed studies, we envisaged the importance of having in the same structure a hydrogen bond moiety and a basic part in order to obtain a more rigid transition state at the moment of the carbon-carbon bond formation. For this aim, we chose squaramide structures 1a-j (Figure 2) ${ }^{[14]}$ (see Supporting information for the rest of tested structures and screening), synthesized following our one-pot developed procedure. ${ }^{[15]}$

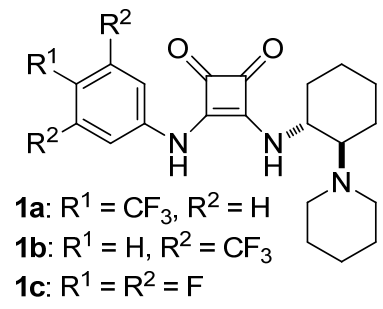<smiles>[R]c1ccc2nccc([C@@H](Nc3c(Nc4cc([R])c([R])c([R])c4)c(=O)c3=O)N3CC4CC3CC4C=C)c2c1</smiles>

1f: $\mathrm{R}^{1}=\mathrm{H}, \mathrm{R}^{2}=\mathrm{CF}_{3}, \mathrm{R}^{3}=\mathrm{H}, \quad$ Epi-CD

1g: $\mathrm{R}^{1}=\mathrm{H}, \mathrm{R}^{2}=\mathrm{CF}_{3}, \mathrm{R}^{3}=\mathrm{OMe}$, Epi-QN

1h: $\mathrm{R}^{1}=\mathrm{CF}_{3}, \mathrm{R}^{2}=\mathrm{H}, \mathrm{R}^{3}=\mathrm{OMe}$, Epi-QN<smiles>CN(C)[C@H]1CCCC[C@H]1Nc1c(Nc2cc(C(F)(F)F)cc(C(F)(F)F)c2)c(=O)c1=O</smiles><smiles>C=CC1CC2CCN1C(c1ccnc3ccc(OC)cc13)[C@@H](Nc1c(NCc3cc(C(F)(F)F)cc(C(F)(F)F)c3)c(=O)c1=O)N2C(=O)ON(C)OC</smiles>

Epi-QN<smiles>O=c1c(NCc2cc(C(F)(F)F)cc(C(F)(F)F)c2)c(N[C@@H]2CCCCC2N2CCCCC2)c1=O</smiles>

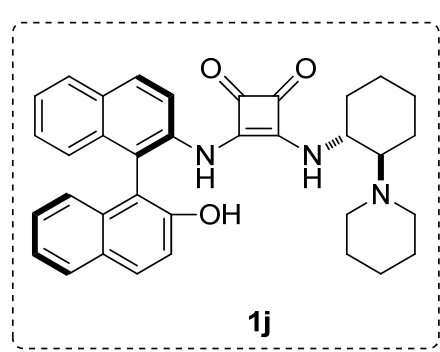

Figure 2. Representative squaramide-based organocatalysts tested.

\section{Results and Discussion}

We started the investigation of the viability of this process examining the efficiency of catalysts 1 in the model reaction between 4-nitrobenzaldehyde (2a) and nitromethane (3a) (see supporting information for the complete outcomes). After a very exhaustive screening of the reaction conditions, novel catalyst $\mathbf{1 j}$ ( $2 \mathrm{~mol} \%$ ) was found to be the catalyst of choice in terms of reactivity and enantioselectivity ( $>95 \%$ yield, $82 \%$ ee, Table 1 , entry 1); nitromethane with no extra solvent resulted the best reaction media, at $-24{ }^{\circ} \mathrm{C}$. The efficiency of the process was further studied for a range of different aldehydes 2a-o (Table 1). 
Table 1. Scope of the squaramide-catalyzed Henry reaction. ${ }^{[a]}$

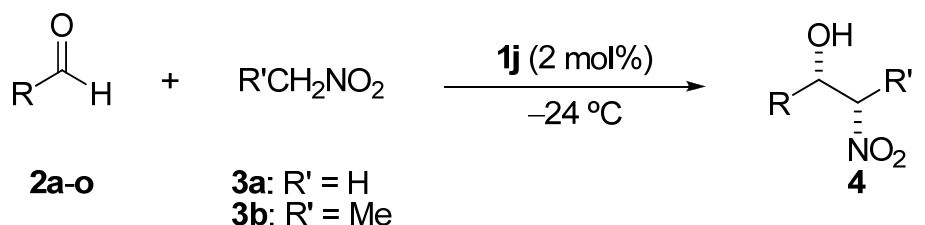

\begin{tabular}{|c|c|c|c|c|c|c|c|}
\hline Entry & $\mathrm{R}$ & $\mathbf{1 j}(\%)$ & $\mathrm{R}^{\prime}$ & $\mathrm{t}(\mathrm{h})$ & product & yield $^{[\mathrm{b}]}(\%)$ & $\mathrm{ee}^{[\mathrm{c}]}(\%)$ \\
\hline 1 & $4-\mathrm{NO}_{2} \mathrm{Ph}(\mathbf{2 a})$ & 2 & H (3a) & 24 & 4aa & $>95$ & 83 \\
\hline 2 & $3-\mathrm{NO}_{2} \mathrm{Ph}(\mathbf{2 b})$ & 2 & $\mathrm{H}(\mathbf{3 a})$ & 24 & $4 \mathrm{ba}$ & $>95$ & 94 \\
\hline 3 & $4-\mathrm{ClPh}(\mathbf{2 c})$ & 2 & $\mathrm{H}(\mathbf{3 a})$ & 91 & $4 c a$ & 81 & 86 \\
\hline 4 & $3-\mathrm{ClPh}(\mathbf{2 d})$ & 2 & $\mathrm{H}(\mathbf{3 a})$ & 86 & 4da & 62 & 90 \\
\hline 5 & 4-BrPh (2e) & 2 & H (3a) & 91 & 4ea & 75 & 86 \\
\hline 6 & 4-CNPh (2f) & 2 & $\mathrm{H}(\mathbf{3 a})$ & 71 & $4 \mathrm{fa}$ & 96 & 82 \\
\hline 7 & 1-Naphthyl (2g) & 2 & $\mathrm{H}(\mathbf{3 a})$ & 86 & $4 g a$ & 50 & 85 \\
\hline 8 & $\mathrm{Ph}(\mathbf{2 h})$ & 2 & $\mathrm{H}(\mathbf{3 a})$ & 86 & 4ha & 59 & 82 \\
\hline 9 & 4-Ph-Ph (2i) & 2.5 & H (3a) & 96 & $4 \mathbf{i a}$ & 50 & 90 \\
\hline 10 & 2-Pyridyl (2j) & 2.5 & $\mathrm{H}(\mathbf{3 a})$ & 96 & $4 \mathbf{j a}$ & $>95$ & 80 \\
\hline 11 & 3-Pyridyl (2k) & 2 & H (3a) & 92 & $4 \mathbf{k a}$ & 95 & 92 \\
\hline 12 & 2-Furyl (2l) & 2 & $\mathrm{H}(\mathbf{3 a})$ & 88 & 4la & 74 & 92 \\
\hline 13 & 2-Thiophenyl (2m) & 2 & $\mathrm{H}(\mathbf{3 a})$ & 92 & $4 \mathrm{ma}$ & 55 & 92 \\
\hline 14 & 4-MePh (2n) & 2 & $\mathrm{H}(\mathbf{3 a})$ & 144 & 4na & 20 & 84 \\
\hline 15 & $\mathrm{PhCH}_{2} \mathrm{OCH}_{2}(\mathbf{2 o})$ & 2 & $\mathrm{H}(\mathbf{3 a})$ & 92 & $40 a$ & 66 & 76 \\
\hline $16^{[\mathrm{d}]}$ & $4-\mathrm{NO}_{2} \mathrm{Ph}(\mathbf{2 a})$ & 2 & $\operatorname{Me}(\mathbf{3 b})$ & 88 & $4 a b$ & $75^{[\mathrm{f}]}$ & $72^{[\mathrm{g}]}$ \\
\hline $17^{[\mathrm{e}]}$ & $3-\mathrm{NO}_{2} \mathrm{Ph}(\mathbf{2 b})$ & 2 & $\mathrm{Me}(\mathbf{3 b})$ & 91 & $4 \mathrm{bb}$ & $74^{[\mathrm{f}]}$ & $88^{[\mathrm{g}]}$ \\
\hline
\end{tabular}

[a] Experimental conditions: to a mixture of catalyst $\mathbf{1 j}(0.0044 \mathrm{mmol})$ in $\mathrm{MeNO}_{2}(1.1 \mathrm{~mL})$, aldehyde $2 \mathbf{a}-\mathbf{0}(0.22$ mmol) was further added in a test tube at $-24{ }^{\circ} \mathrm{C}$. ${ }^{[b]}$ After isolation by column chromatography. ${ }^{[\mathrm{c}]}$ Determined by chiral HPLC analysis. ${ }^{[\mathrm{d}]}$ d.r. 1:1.3 anti:syn. ${ }^{[\mathrm{e}]}$ d.r. 1:1.4 anti:syn. ${ }^{[\mathrm{f}]}$ Yield as mixture of both diasteroisomers. ${ }^{[\mathrm{g}]}$ Enantiomeric excess (ee) for the major diasteroisomer.

The Henry reaction took place rendering the desired $\beta$-nitroalcohols 4 in good to excellent yields (up to $>95 \%$ ) and high enantioselectivities (up to $94 \%$ ) with very clean reaction crudes. The effectiveness of the developed procedure is well accounted since it was successfully applied to a representative set of aldehydes 2a-o. The enantioselectivity was not dependent on the electronic effects of the aldehydes. However, the reactivity suggests a close correlation with the electronegativity of the aldehyde since those with an electro-withdrawing group in the aromatic ring exhibited more reactivity. In fact, in the case of aldehyde $2 \mathbf{n}$ the reaction was slower, although keeping the good enantioselectivity of the process (entry 14). At this point, it is important to remark that we have observed that the presence of traces of acid in the aldehydes could inactivate the catalyst used at this small scale, and many of the aldehydes were previously treated in order to avoid such inactivation. This fact is in agreement with the lack of background for this reaction in the absence of a base. The absolute configuration of final adducts 4 was determined by comparison of their optical rotation values with those previously reported in the literature for the same products and it was found to be $S$ (see experimental section for optical rotation values).

We further evaluated the grade of effectiveness of the catalytic system lowering even more the catalyst loading for four representative aldehydes (2a,b,f,p) (Table 2). 
Table 2. Study of the catalyst loading for the Henry reaction. ${ }^{[a]}$

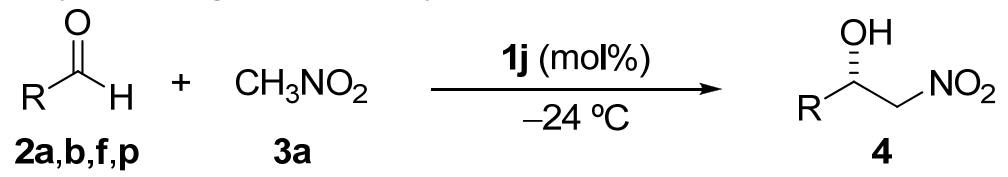

\begin{tabular}{|c|c|c|c|c|c|}
\hline Entry & $\mathrm{R}$ & $1 \mathrm{j}(\%)$ & $\mathrm{t}(\mathrm{h})$ & yield $^{[b]}(\%)$ & $\mathrm{ee}^{[\mathrm{cc}]}(\%)$ \\
\hline 1 & $4-\mathrm{NO}_{2} \mathrm{Ph}(\mathbf{2 a})$ & 1 & 24 & $>95$ & 82 \\
\hline $2^{[\mathrm{d}]}$ & 4- $\mathrm{NO}_{2} \mathrm{Ph}(\mathbf{2 a})$ & 0.5 & 76 & $>95$ & 82 \\
\hline $3^{[e]}$ & $4-\mathrm{NO}_{2} \mathrm{Ph}(\mathbf{2 a})$ & 0.25 & 92 & 86 & 82 \\
\hline 4 & $3-\mathrm{NO}_{2} \mathrm{Ph}(\mathbf{2 b})$ & 1 & 24 & $>95$ & 94 \\
\hline $5^{\text {[d] }}$ & $3-\mathrm{NO}_{2} \mathrm{Ph}(\mathbf{2 b})$ & 0.5 & 76 & $>95$ & 94 \\
\hline $6^{[\mathrm{e}]}$ & $3-\mathrm{NO}_{2} \mathrm{Ph}(\mathbf{2 b})$ & 0.25 & 95 & 92 & 94 \\
\hline $7^{[\mathrm{f}]}$ & $3-\mathrm{NO}_{2} \mathrm{Ph}(\mathbf{2 b})$ & 0.25 & 96 & $>95$ & 94 \\
\hline 8 & 4-CNPh (2f) & 1 & 95 & $>95$ & 82 \\
\hline $9^{[\mathrm{d}]}$ & $4-\mathrm{CNPh}(\mathbf{2 f})$ & 0.5 & 100 & $>95$ & 82 \\
\hline $10^{[\mathrm{e}]}$ & $4-\mathrm{CNPh}(\mathbf{2 f})$ & 0.25 & 92 & 59 & 82 \\
\hline $11^{[\mathrm{d}]}$ & $\mathrm{F}_{5} \mathrm{C}_{5}(\mathbf{2 p})$ & 0.5 & 45 & $>95$ & 86 \\
\hline $12^{[\mathrm{e}]}$ & $\mathrm{F}_{5} \mathrm{C}_{5}(\mathbf{2 p})$ & 0.25 & 120 & $>95$ & 86 \\
\hline
\end{tabular}

${ }^{[a]}$ Experimental conditions: to a mixture of catalyst $\mathbf{1} \mathbf{j}$ in $\mathrm{MeNO}_{2}(1.1 \mathrm{~mL})$, aldehyde $\mathbf{2 a}, \mathbf{b}, \mathbf{f}, \mathbf{p}(0.22 \mathrm{mmol})$ was further added in a test tube at $-24^{\circ} \mathrm{C}$. After the reaction time, adduct $\mathbf{4}$ was isolated by flash chromatography. ${ }^{[b]}$ After isolation by column chromatography. ${ }^{[c]}$ Determined by chiral HPLC analysis. ${ }^{[\mathrm{d}]}$ Conditions for the use of $0.44 \mathrm{mmol}$ of aldehyde. ${ }^{[\mathrm{e}]}$ Conditions for the use of $0.88 \mathrm{mmol}$ of aldehyde. ${ }^{[\mathrm{f}]}$ Reaction performed at higher scale to obtain 1 gram of product.

As disclosed in Table 2, interestingly, we were able to decrease the catalyst loading to $0.25 \mathrm{~mol} \%$, one of the lowest value used in a Henry protocol and one of the lowest amounts employed so far in organocatalysis. $^{[3]}$ In all cases, the same enantioselectivity was found, although after longer reaction times. It is worth noting that this system allows scaling up the reaction, since the same excellent results, in terms of enantioselectivity and reactivity, were afforded when it was set up to obtain 1 gram of final product (Table 2, entry 7).

We continued our investigations exploring the effect of some designed changes in the structure of the catalyst, in order to understand the role played by novel catalyst $\mathbf{1} \mathbf{j}$, which bears different functionalities (Scheme 1). Thus, catalyst $\mathbf{1 k}$, which has the opposite configuration $(S)$ on the binaphthyl scaffold compared to catalyst $\mathbf{1 j}(R)$, was prepared in order to study the possible match/mismatch effect. Interestingly, no reversal of the sense in the asymmetric induction was observed, giving rise to the same absolute enantiomer in the final product. However, final product $\mathbf{4 b a}$ was achieved with lower ee value compared to catalyst $\mathbf{1 j}$ ( $81 \%$ vs $94 \%$ ee). This suggests that the sense of the enantioinduction of this process seems to be directly depending on the 2-(1-piperidinyl)cyclohexylamine moiety, but the different value of enantioselectivity obtained reveals an influence of the binaphthyl ring in the different reaction pathways.<smiles>O=C([18O])c1cccc([N+](=O)[O-])c1</smiles><smiles>O=C1C(=O)C(NC2CCCCC2N2CCCCC2)C1Nc1ccc2ccccc2c1-c1c(O)ccc2ccccc12</smiles>

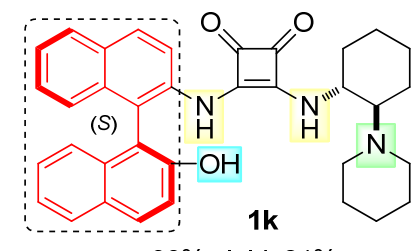
$90 \%$ yield, $81 \%$ ee

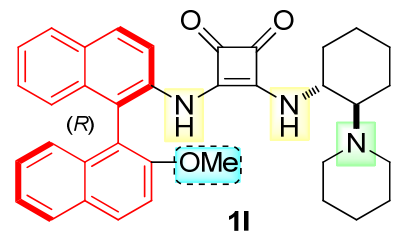

$91 \%$ yield, $92 \%$ ee

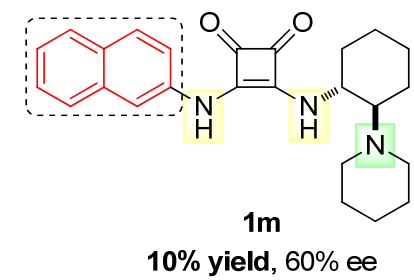

Scheme 1. Additional squaramide-based organocatalysts $1 \mathbf{k}-\mathbf{m}$ tested.

The reaction using catalyst $\mathbf{1 l}$ (with a OMe group instead of a free $\mathrm{OH}$ ) leads to the same good results obtained with catalyst $\mathbf{1 j}$. Therefore, it seems that the binaphthyl skeleton could be crucial in stabilizing the TS to properly induce better enantioselectivity, even when the participation of the $\mathrm{OR}(\mathrm{R}=\mathrm{H}$ or $\mathrm{Me})$ group in the process is still unclear at this stage. Interestingly, when we performed the reaction with catalyst 1m (with a naphthyl moiety instead of the binaphthyl fragment present in $\mathbf{1 j}$ ), the reactivity and the enantioselectivity of the process drastically dropped $(10 \%$ yield, $60 \%$ ee). Also, catalyst $\mathbf{1 j}$ showed much better results compared to those obtained with other squaramides whose structures 
only differ in their aromatic moieties, such as 1a-c and 1e (entry 6 in Table S2 and entries 1, 7 and 8 in Table S3, respectively). This fact confirms the necessity of the complete binaphthyl structure in catalyst $\mathbf{1} \mathbf{j}$ for the success of the process.

In order to explain the role of the multifunctional catalyst $\mathbf{1} \mathbf{j}$, based on the experimental results and computational calculations (see ESI), a reasonable reaction pathway is proposed for the Henry reaction between 4-cyanobenzaldehyde (2f) and nitromethane (3a) (only the rate-limiting step is shown for simplicity) (Figure 2).

TSa
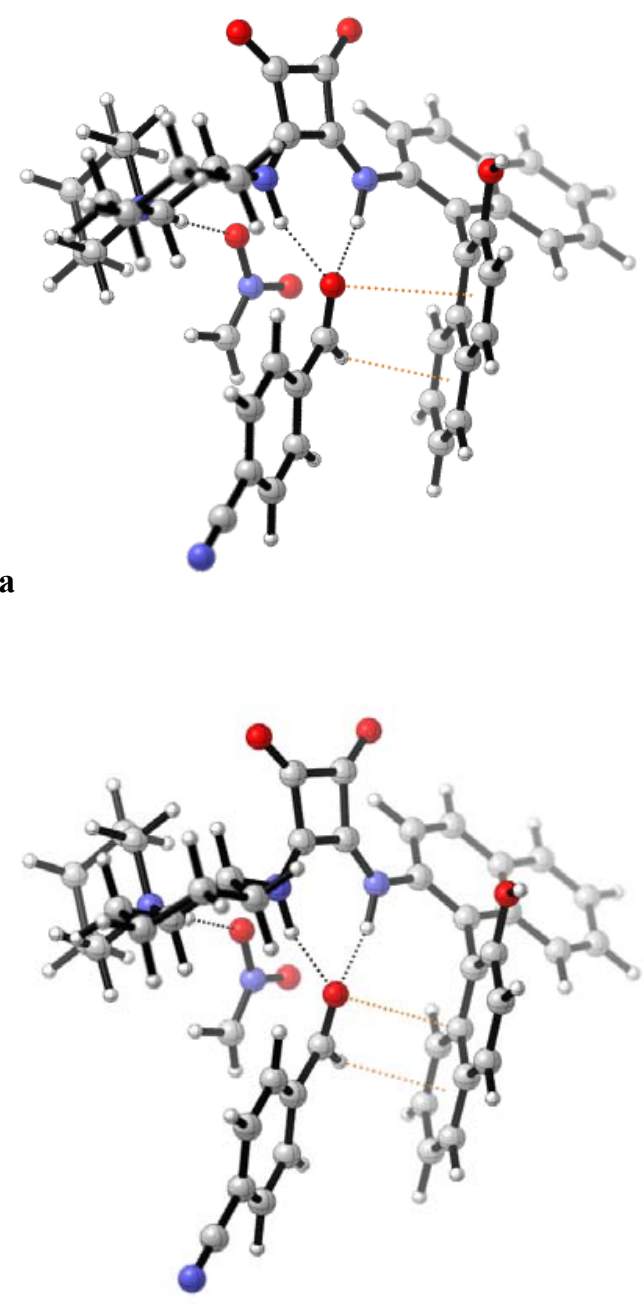

TSb

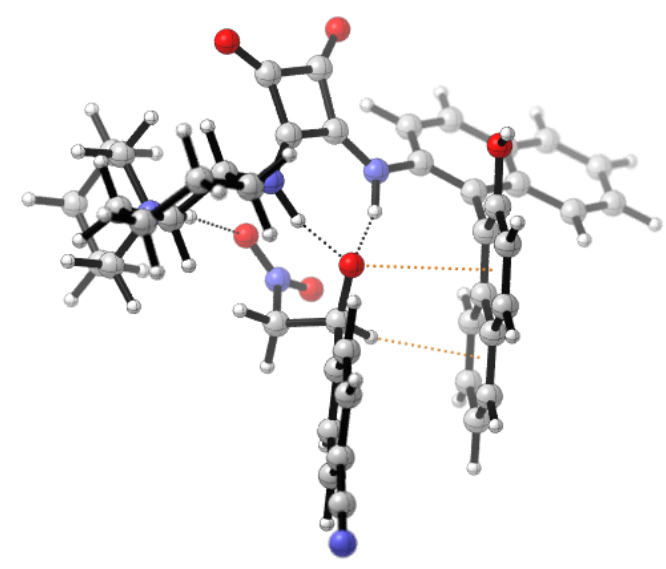

TSc

Figure 2. TSa: catalyst-substrates complex before nitronate attack, TSb: transition state (TS) of the nitronate attack, and TSc: catalyst-intermediate product complex after the nitronate attack. All DFT calculations were carried out with the Gaussian 09 software ${ }^{[16]}$ at the

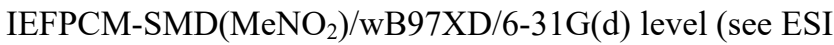
for more information about computational details).

The $\mathrm{O}$ atom of the aldehyde, which is developing a negative charge during the advance of the reaction, and the $\mathrm{H}$ atom of the aldehyde are interacting with the $\pi$-system of the catalyst in the most energetically favorable reaction pathway (see ESI for additional TSs).

In order to support these $\pi$ interactions, the density maps of the non-covalent interactions for TSa-c have been also calculated (Figures 3-5). These maps show hydrogen bonds between the aldehyde and the squaramide moiety through double hydrogen bonding with the $\mathrm{NH}$ groups and between the basic nitrogen atom on the piperidine and the nitromethane. These non-covalent interactions are represented in blue color.

Moreover, the $\pi$ interactions between the aldehyde and the binaphthyl moiety are also disclosed. These interactions are shown in green color, being weaker than those represented in blue color (Figures 3-5). 

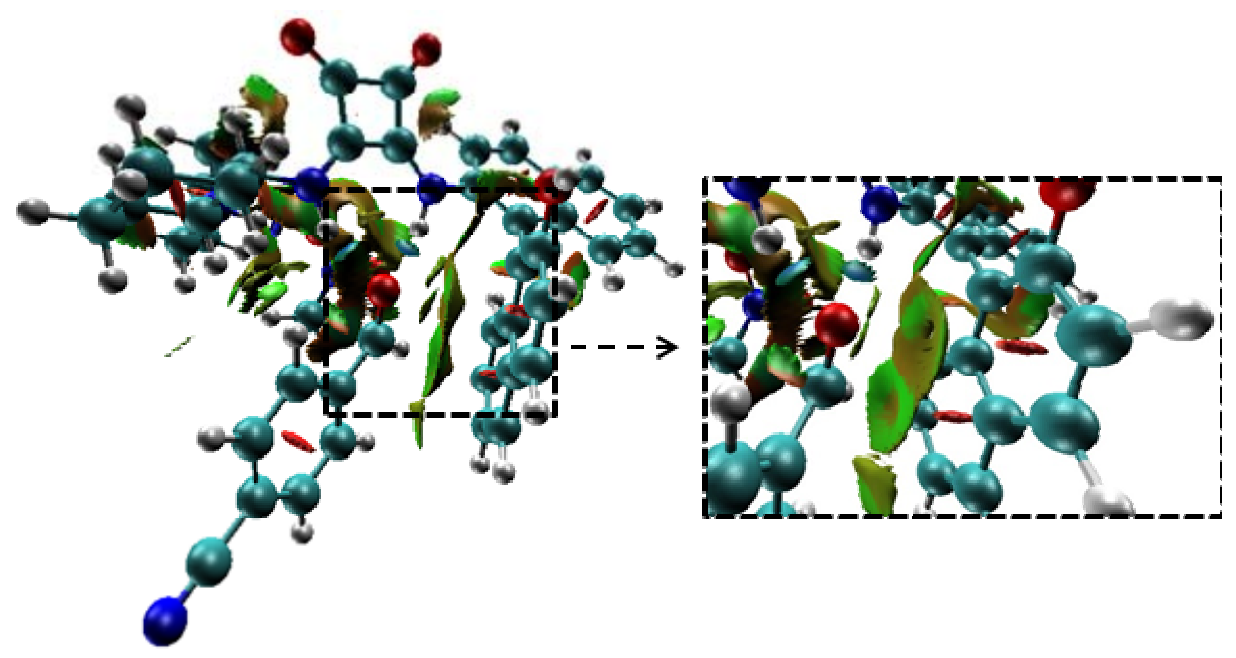

Figure 3. Electronic density map of system TSa: green and blue regions represent attractive VdW interactions. ${ }^{[17]}$ Grid data for sign $(\lambda 2) \rho$ and RDG was generated using Multiwfn. ${ }^{[18]}$ The image was created using VMD. ${ }^{[19]}$

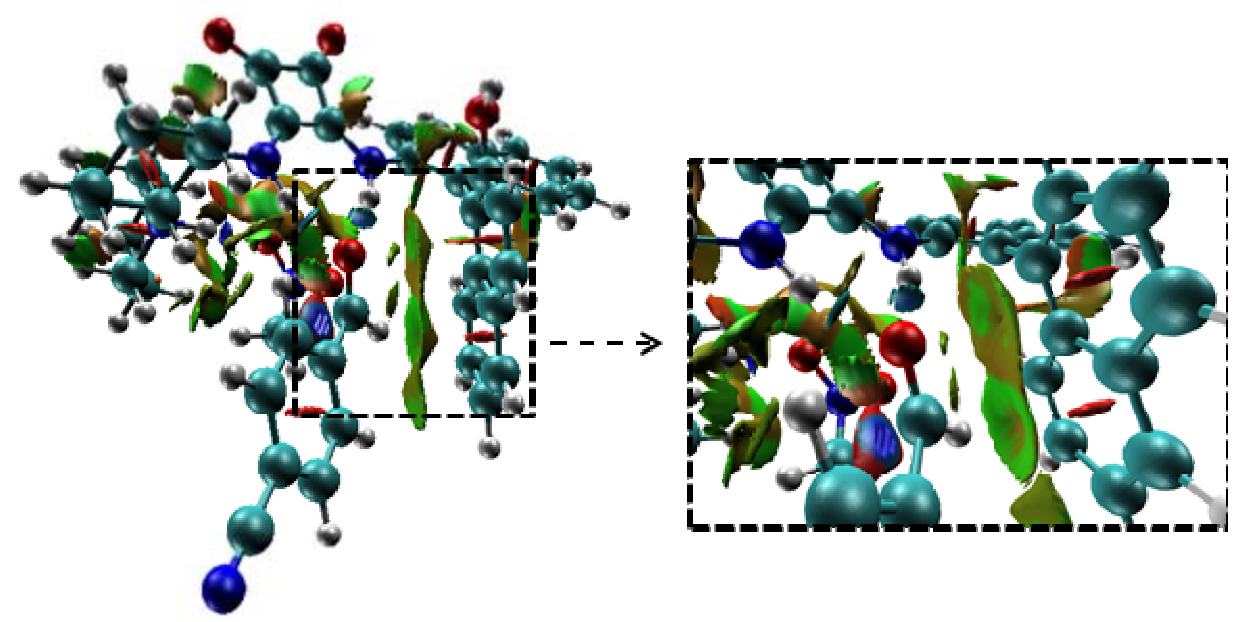

Figure 4. Electronic density map of TSb: green and blue regions represent attractive VdW interactions. ${ }^{[17]}$ Grid data for $\operatorname{sign}(\lambda 2) \rho$ and RDG was generated using Multiwfn. ${ }^{[18]}$ The image was created using VMD. ${ }^{[19]}$

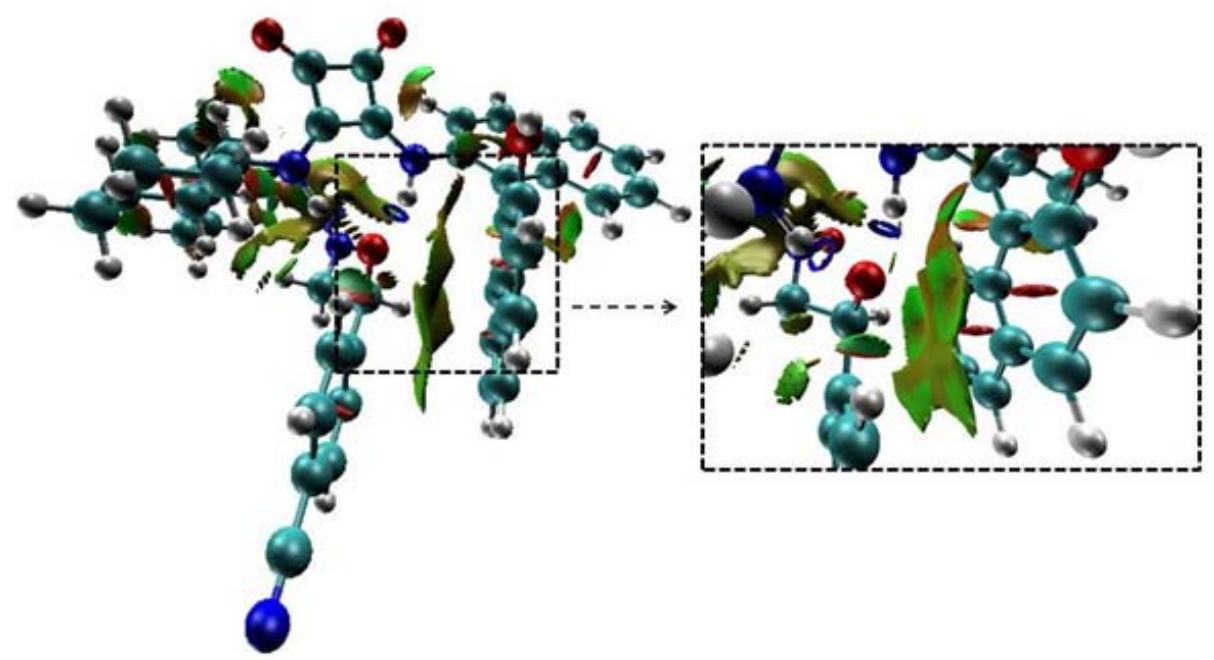

Figure 5. Electronic density map of TSc: green and blue regions represent attractive VdW interactions. ${ }^{[17]}$ Grid data for $\operatorname{sign}(\lambda 2) \rho$ and RDG was generated using Multiwfn. ${ }^{[18]}$ The image was created using VMD.$^{[19]}$ 
Thus, catalyst $\mathbf{1} \mathbf{j}$ could be acting in a trifunctional fashion. First, the aldehyde would be activated by the squaramide moiety through double hydrogen bonding with the NH groups. At the same time, the $\pi$-system of the binaphthyl scaffold would stabilize the TS and would activate the aldehyde for the subsequent attack. Additionally, the basic nitrogen atom on the piperidine ring would activate the nitromethane, allowing the attack of the nitronate form over the $R e$ face of the aldehyde. This attack would afford the $S$ absolute configuration in all final products, which is consistent with the observed results. Moreover, this attack would be in agreement with the control of the sense in the enantioinduction by the 2-(1piperidinyl)cyclohexylamine moiety.

Beyond the steric influence caused by the binaphthyl moiety that can orientate the disposition of the reagents in the TS, we believe that the noncovalent interactions between this group and the aldehyde influence both, the reactivity and the enantioselectivity of the process. This anion- $\pi$ interaction would stabilize the energetic barrier of the $\mathrm{TS}$, increasing the reaction rate of the process and, consequently, the origin of the catalysis would also rely in this weak but effective effect. This interaction ensures a more energetically favorable TS where the chiral catalyst remains in close proximity to the electrophile during the enantioselectivity-determining step of the catalytic cycle. The presence of these secondary binding is able to provide a higher degree of organization in the transition state, necessary for a high enantioinduction. Moreover, the lower enantioselectivity observed with catalyst $\mathbf{1 m}$ compared with $\mathbf{1 j}$, would also be in agreement with the importance of the presence of the binaphthyl scaffold to organize a more stable TS.

\section{Conclusion}

In conclusion, a new class of chiral squaramide catalyst acting by mean of multiple interactions has been developed to efficiently catalyze the Henry reaction with very good results. Novel trifunctional catalyst $\mathbf{1} \mathbf{j}$ is able to generate hydrogen bonding and anion- $\pi$ interactions with the substrates, which are responsible of the improvement in the reactivity and the stereoselectivity of the process. This active catalyst was found to provide excellent values of enantioselectivity and reactivity even at $0.25 \mathrm{~mol} \%$ catalyst loading, one of the lowest amounts for this reaction using organocatalysts. A unique example of anion- $\pi$ effect has been described for the first time in asymmetric catalysis, and this feature makes catalyst 1j a plausible trifunctional catalyst. Further investigations of the efficacy of this organocatalyst in other catalytic asymmetric reactions, as well as additional computational and NMR studies, are ongoing in our lab in order to support the singular activation mode proposed herein.

\section{Experimental Section}

General experimental methods. Purification of reaction products was carried out either by filtration or by flash chromatography using silical-gel (0.063-0.200 $\mathrm{mm})$. Analytical thin layer chromatography was performed on $0.25 \mathrm{~mm}$ silical gel $60-\mathrm{F}$ plates. ESI ionization method and mass analyzer type MicroTof-Q were used for the ESI measurements. ${ }^{1} \mathrm{H}-\mathrm{NMR}$ spectra were recorded at 300 and $400 \mathrm{MHz} ;{ }^{13} \mathrm{C}$-APT-NMR spectra were recorded at 75 and $100 \mathrm{MHz} ; \mathrm{CDCl}_{3}, \mathrm{CD}_{3} \mathrm{CN}$ and DMSO- $d_{6}$ were used as the deuterated solvents. Chemical shifts were reported in the $\delta$ scale relative to residual $\mathrm{CHCl}_{3}(7.26 \mathrm{ppm}), \mathrm{MeCN}$ (1.94 $\mathrm{ppm})$ and DMSO (2.50 ppm) for ${ }^{1} \mathrm{H}-\mathrm{NMR}$ and to the central line of $\mathrm{CDCl}_{3}(77 \mathrm{ppm}), \mathrm{CD}_{3} \mathrm{CN}(1.24 \mathrm{ppm})$ and DMSO- $d_{6}(39.43 \mathrm{ppm})$ for ${ }^{13} \mathrm{C}$-APT-NMR.

Materials. Spectral data for $\mathbf{1 b},{ }^{[20]} \mathbf{1 c},{ }^{[21]} \mathbf{1 d},{ }^{[22]} \mathbf{1 e},{ }^{[23]}$ $\mathbf{1 f},{ }^{[22]} \mathbf{1 g},{ }^{[22]} \mathbf{1 h},,^{[22]} \mathbf{1 i},{ }^{[24]} \mathbf{1 j},^{[21]} \mathbf{1 n},,^{[21]} \mathbf{1 0},,^{[21]} \mathbf{1 p},,^{[21]}$ and $\mathbf{1 \mathbf { q } ^ { [ 2 1 ] }}$ are consistent with values previously reported in the literature. For the synthesis and spectra of catalysts $1 \mathbf{k}-\mathbf{m}$ see supporting information.

Representative procedure for the squaramideorganocatalyzed Henry reaction of aldehydes

To a mixture of catalyst $\mathbf{1 j}(0.0044 \mathrm{mmol}$ unless otherwise stated in Table 1) and aldehyde 2 a-o $(0.22 \mathrm{mmol})$, was added $\mathrm{MeNO}_{2}(1.1 \mathrm{~mL})$ in a test tube at $-24^{\circ} \mathrm{C}$. After the reaction time (see Table 1 and 2), adducts 4 were isolated by flash chromatography $\left(\mathrm{SiO}_{2}\right.$, using Hex:EtOAc $9: 1$ to Hex:EtOAc 7:3). Yields and enantioselectivities are reported in Table 1. If acid traces were observed in the aldehydes by NMR, these aldehydes were previously purified by column chromatography (very short column, eluted with $\mathrm{CH}_{2} \mathrm{Cl}_{2}$ or $\mathrm{MeCN}$ ) or extraction (dissolving these aldehydes in $\mathrm{CH}_{2} \mathrm{Cl}_{2}$ and washing with a $0.3 \mathrm{M}$ solution of $\mathrm{NaOH}$ ). Then, the $\mathrm{CH}_{2} \mathrm{Cl}_{2}$ was evaporated in vacuum and the aldehydes were used within 2-5 minutes to avoid acid formation.

(S)-2-Nitro-1-(4-nitrophenyl)ethanol (4aa) ${ }^{[25]}$ Following the general procedure, compound $4 \mathbf{a a}$ was obtained after $24 \mathrm{~h}$ of reaction at $-24{ }^{\circ} \mathrm{C}$ as a dark green oil in $>95 \%$ yield. The ee of the product was determined to be $83 \%$ by HPLC using a Daicel Chiralpak IA column $(n$-hexane/ $i$ $\mathrm{PrOH}=80: 20$, flow rate $\left.1 \mathrm{~mL} \mathrm{~min}^{-1}, \lambda=230.3 \mathrm{~nm}\right): \tau_{\text {major }}$ $=15.6 \mathrm{~min} ; \tau_{\text {minor }}=12.1 \mathrm{~min} .[\alpha]_{\mathrm{D}}{ }^{28}=+23.2(\mathrm{c} 1.30$, $\mathrm{CHCl}_{3}, 82 \%$ ee) $\left\{\right.$ lit., ${ }^{[25]}[\alpha]_{\mathrm{D}}{ }^{24}-30.4\left(c 0.53, \mathrm{CHCl}_{3}\right)$ for $(R)-\mathbf{4 a a}, 88 \%$ ee $\}$.

(S)-2-Nitro-1-(3-nitrophenyl)ethanol (4ba) ${ }^{[26]}$ Following the general procedure, compound $\mathbf{4 b a}$ was obtained after $24 \mathrm{~h}$ of reaction at $-24^{\circ} \mathrm{C}$ as a dark green solid in $>95 \%$ yield. The ee of the product was determined to be $94 \%$ by HPLC using a Daicel Chiralpak IB column ( $n$-hexane $/ i$ $\mathrm{PrOH}=80: 20$, flow rate $\left.1 \mathrm{~mL} \mathrm{~min}^{-1}, \lambda=281.7 \mathrm{~nm}\right): \tau_{\text {major }}$ $=10.5 \mathrm{~min} ; \tau_{\text {minor }}=9.9 \mathrm{~min} .[\alpha]_{\mathrm{D}}{ }^{23}=+27.2\left(c 0.33, \mathrm{CHCl}_{3}\right.$, $94 \%$ ee) $\left\{\right.$ lit., ${ }^{[26]}[\alpha]_{\mathrm{D}}{ }^{26}-27.4\left(c 0.87, \mathrm{CH}_{2} \mathrm{Cl}_{2}\right)$ for $(R)-4 \mathbf{b a}$, $96 \%$ ee $\}$.

(S)-1-(4-Chlorophenyl)-2-nitroethanol

$(4 \mathrm{ca})^{[25]}$

Following the general procedure, and purifying the aldehyde by column chromatography (eluted with $\mathrm{CH}_{2} \mathrm{Cl}_{2}$ ), compound 4ca was obtained after $91 \mathrm{~h}$ of reaction at 
$-24{ }^{\circ} \mathrm{C}$ as a dark brown oil in $81 \%$ yield. The ee of the product was determined to be $86 \%$ by HPLC using a Daicel Chiralpak IB column ( $n$-hexane $/ i-\mathrm{PrOH}=90: 10$, flow rate $\left.1 \mathrm{~mL} \min ^{-1}, \lambda=230.1 \mathrm{~nm}\right): \tau_{\text {major }}=12.6 \mathrm{~min}$; $\tau_{\text {minor }}=11.1$ min. $[\alpha]_{\mathrm{D}}{ }^{23}=+27.2\left(c 0.31, \mathrm{CHCl}_{3}, 86 \%\right.$ ee $)$ $\left\{\right.$ lit., ${ }^{[25]}[\alpha]_{\mathrm{D}}{ }^{22}-38.8\left(c 0.55, \mathrm{CHCl}_{3}\right)$ for $(R)-4 \mathbf{c a}, 90 \%$ ee $\}$.

\section{(S)-1-(3-Chlorophenyl)-2-nitroethanol}

$(4 d a)^{[27]}$ Following the general procedure, and purifying the aldehyde 2d by basic washing, compound 4da was obtained after $86 \mathrm{~h}$ of reaction at $-24{ }^{\circ} \mathrm{C}$ as a dark brown oil in $62 \%$ yield. The ee of the product was determined to be $90 \%$ by HPLC using a Daicel Chiralpak IB column ( $n$ hexane $/ i-\mathrm{PrOH}=90: 10$, flow rate $1 \mathrm{~mL} \min ^{-1}, \lambda=226.2$ $\mathrm{nm}): \tau_{\text {major }}=11.8 \mathrm{~min} ; \tau_{\text {minor }}=10.3 \mathrm{~min} .[\alpha]_{\mathrm{D}}{ }^{24}=+24.8(\mathrm{c}$ $1.4, \mathrm{CHCl}_{3}, 90 \%$ ee) $\left\{\right.$ lit., ${ }^{[27]}[\alpha]_{\mathrm{D}}{ }^{27}+31.17\left(c 1.0, \mathrm{CHCl}_{3}\right)$ for $95 \%$ ee\}.

\section{(S)-1-(4-Bromophenyl)-2-nitroethanol}

$(4 \mathbf{e a})^{[28]}$ Following the general procedure, and purifying the aldehyde $2 \mathrm{e}$ by column chromatography (eluted with $\mathrm{CH}_{2} \mathrm{Cl}_{2}$ ), compound 4ea was obtained after $91 \mathrm{~h}$ of reaction at $-24{ }^{\circ} \mathrm{C}$ as a dark brown oil in $75 \%$ yield. The ee of the product was determined to be $86 \%$ by HPLC using a Daicel Chiralpak IA column ( $n$-hexane $/ i-\mathrm{PrOH}=90: 10$, flow rate $1 \mathrm{~mL} \min ^{-1}, \lambda=237.2 \mathrm{~nm}$ ): $\tau_{\text {major }}=14.9 \mathrm{~min}$; $\tau_{\text {minor }}=12.2$ min. $[\alpha]_{\mathrm{D}}{ }^{23}=+20.1\left(c 0.27, \mathrm{CHCl}_{3}, 86 \%\right.$ ee $)$ $\left\{\right.$ lit., ${ }^{[28]}[\alpha]_{\mathrm{D}}{ }^{23}-68.6\left(c 1.40, \mathrm{CHCl}_{3}\right)$ for $(R)-4 \mathrm{ea}, 89 \%$ ee $\}$.

\section{(S)-4-(1-Hydroxy-2-nitroethyl)benzonitrile}

$(4 \mathbf{f a})^{[29]}$ Following the general procedure, compound $\mathbf{4 f a}$ was isolated by flash chromatography after $71 \mathrm{~h}$ of reaction at $-24{ }^{\circ} \mathrm{C}$ as a pale brown solid in $>95 \%$ yield. The ee of the product was determined to be $82 \%$ by HPLC using a Daicel Chiralpak IB column ( $n$-hexane $/ i-\mathrm{PrOH}=90: 10$,

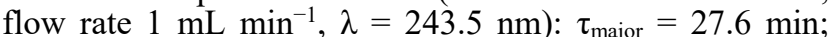
$\tau_{\text {minor }}=25.3 \mathrm{~min} .[\alpha]_{\mathrm{D}}{ }^{24}=+36.3\left(c 0.74, \mathrm{CHCl}_{3}, 81 \%\right.$ ee $)$ $\left\{\right.$ lit., ${ }^{[30]}[\alpha]_{\mathrm{D}}{ }^{20}-32.8\left(c 0.50, \mathrm{CH}_{2} \mathrm{Cl}_{2}\right)$ for $(R)-\mathbf{4 f a}, 90 \%$ ee $\}$

\section{(S)-1-(Naphthalen-1-yl)-2-nitroethanol}

$(4 g a)^{[25]}$ Following the general procedure, and purifying the aldehyde $\mathbf{2 g}$ by basic washing, compound 4ga was obtained after $86 \mathrm{~h}$ of reaction at $-24{ }^{\circ} \mathrm{C}$ as a dark brown oil in $50 \%$ yield. The ee of the product was determined to be $85 \%$ by HPLC using a Daicel Chiralpak IB column ( $n$ hexane $/ i$-PrOH $=90: 10$, flow rate $1 \mathrm{~mL} \min ^{-1}, \lambda=254.0$ $\mathrm{nm}): \tau_{\text {major }}=14.5 \mathrm{~min} ; \tau_{\text {minor }}=11.6 \mathrm{~min} .[\alpha]_{\mathrm{D}}{ }^{27}=+19.1(\mathrm{c}$ $0.85, \mathrm{CHCl}_{3}, 85 \%$ ee $)\left\{\right.$ lit., ${ }^{[25]}[\alpha]_{\mathrm{D}^{21}}+24.5$ (c $0.53, \mathrm{CHCl}_{3}$, for $(S)-4 g a, 88 \%$ ee

(S)-2-Nitro-1-phenylethanol (4ha) ${ }^{[31]}$ Following the general procedure, and purifying the aldehyde $\mathbf{2 h}$ by basic washing, compound 4ha was obtained after $86 \mathrm{~h}$ of reaction at $-24{ }^{\circ} \mathrm{C}$ as a dark brown oil in $59 \%$ yield. The ee of the product was determined to be $82 \%$ by HPLC using a Daicel Chiralpak IB column ( $n$-hexane $/ i-\mathrm{PrOH}=90: 10$, flow rate $\left.1 \mathrm{~mL} \min ^{-1}, \lambda=248.1 \mathrm{~nm}\right): \tau_{\text {major }}=11.3 \mathrm{~min}$; $\tau_{\text {minor }}=10.1$ min. $[\alpha]_{\mathrm{D}}{ }^{25}=+11.9\left(c 1.1, \mathrm{CH}_{2} \mathrm{Cl}_{2}, 82 \%\right.$ ee $)$ $\left\{\right.$ lit., ${ }^{[31]}[\alpha]_{\mathrm{D}}{ }^{21}-41.6\left(c 1.03, \mathrm{CH}_{2} \mathrm{Cl}_{2}\right)$ for $(R)-4$ ha, $94 \%$ ee $\}$.

\section{(S)-1-([1,1'-Biphenyl]-4-yl)-2-nitroethanol}

$(4 i a)^{[31]}$ Following the general procedure, compound 4ia was isolated by flash chromatography after $96 \mathrm{~h}$ of reaction at $-24{ }^{\circ} \mathrm{C}$ as a yellow solid in $50 \%$ yield. Mp. $127-129^{\circ} \mathrm{C}$. ${ }^{[31]}$ The ee of the product was determined to be $90 \%$ by HPLC using a Daicel Chiralpak IB column $(n$-hexane $/ i$-PrOH $=$ 90:10, flow rate $\left.1 \mathrm{~mL} \min ^{-1}, \lambda=231.2 \mathrm{~nm}\right): \tau_{\text {major }}=16.3$ min; $\tau_{\text {minor }}=13.3$ min. $[\alpha]_{\mathrm{D}}^{23}=+25.8\left(c 0.47, \mathrm{CHCl}_{3}, 88 \%\right.$ ee) $\left\{\right.$ lit., ${ }^{[31]}[\alpha]_{\mathrm{D}}{ }^{23}-36.1\left(c 1.35, \mathrm{CH}_{2} \mathrm{Cl}_{2}\right)$ for $(R)-4 \mathrm{ia}, 91 \%$ ee $\}$.
(S)-2-Nitro-1-(pyridin-2-yl)ethanol (4ja) ${ }^{[32]}$ Following the general procedure, and purifying the aldehyde $2 \mathbf{j}$ by column chromatography (eluted with $\mathrm{MeCN}$ ), compound 4ja was isolated by flash chromatography $\left(\mathrm{SiO}_{2}\right.$, using Hex:EtOAc 8:2 to Hex:EtOAc 1:1) after $96 \mathrm{~h}$ of reaction at $-24{ }^{\circ} \mathrm{C}$ as a dark brown oil in $>95 \%$ yield. The ee of the product was determined to be $80 \%$ by HPLC using a Daicel Chiralpak IA column ( $n$-hexane $/ i$-PrOH $=90: 10$, flow rate $\left.1 \mathrm{~mL} \min ^{-1}, \lambda=218.4 \mathrm{~nm}\right): \tau_{\text {major }}=12.1 \mathrm{~min}$; $\tau_{\text {minor }}=15.3 \mathrm{~min} .[\alpha]_{\mathrm{D}}{ }^{24}=+49.8\left(c 0.16, \mathrm{CHCl}_{3}, 80 \%\right.$ ee $)$.

(S)-2-Nitro-1-(pyridin-3-yl)ethanol (4ka) ${ }^{[33]}$ Following the general procedure, and purifying the aldehyde $\mathbf{2 k}$ by column chromatography (eluted with $\mathrm{MeCN}$ ), compound 4ka was isolated by flash chromatography $\left(\mathrm{SiO}_{2}\right.$, using Hex:EtOAc 7:3 to Hex:EtOAc 2:8) after $92 \mathrm{~h}$ of reaction at $-24{ }^{\circ} \mathrm{C}$ as a dark brown oil in $95 \%$ yield. The ee of the product was determined to be $92 \%$ by HPLC using a Daicel Chiralpak IA column $(n$-hexane $/ i-\mathrm{PrOH}=90: 10$, flow rate $\left.1 \mathrm{~mL} \min ^{-1}, \lambda=240.2 \mathrm{~nm}\right): \tau_{\text {major }}=24.3 \mathrm{~min}$; $\tau_{\text {minor }}=28.3 \mathrm{~min} .[\alpha]_{\mathrm{D}}{ }^{29}=+35.1($ c $0.23, \mathrm{MeCN}, 92 \%$ ee $)$.

(R)-1-(Furan-2-yl)-2-nitroethanol (4la) ${ }^{[34]}$ Following the general procedure, and purifying the aldehyde $\mathbf{2 1}$ by column chromatography (eluted with $\mathrm{CH}_{2} \mathrm{Cl}_{2}$ ), compound 4la was obtained after $88 \mathrm{~h}$ of reaction at $-24^{\circ} \mathrm{C}$ as a dark brown oil in $74 \%$ yield. The ee of the product was determined to be $92 \%$ by HPLC using a Daicel Chiralpak IA column ( $n$-hexane $/ i-\mathrm{PrOH}=90: 10$, flow rate $1 \mathrm{~mL}$ $\left.\min ^{-1}, \lambda=224.8 \mathrm{~nm}\right): \tau_{\text {major }}=10.9 \mathrm{~min} ; \tau_{\text {minor }}=10.2 \mathrm{~min}$ $[\alpha]_{\mathrm{D}}{ }^{29}=+36.3\left(c 0.16, \mathrm{CHCl}_{3}, 92 \%\right.$ ee $)\left\{\right.$ lit. ${ }^{[29]}[\alpha]_{\mathrm{D}}{ }^{23}$ -36.7 (c 2.72, $\left.\mathrm{CHCl}_{3}\right)$ for $(S)-4 \mathbf{l a}, 85 \%$ ee $\}$.

(R)-2-Nitro-1-(thiophen-2-yl)ethanol (4ma) ${ }^{[34]}$ Following the general procedure, and purifying the aldehyde $2 \mathbf{m}$ by column chromatography (eluted with $\mathrm{CH}_{2} \mathrm{Cl}_{2}$ ), compound $4 \mathrm{ma}$ was obtained after $92 \mathrm{~h}$ of reaction at $-24{ }^{\circ} \mathrm{C}$ as a dark brown oil in 55\% yield. The ee of the product was determined to be $92 \%$ by HPLC using a Daicel Chiralpak IB column ( $n$-hexane $/ i-\mathrm{PrOH}=90: 10$, flow rate $1 \mathrm{~mL}$ $\left.\min ^{-1}, \lambda=246.6 \mathrm{~nm}\right): \tau_{\text {major }}=12.0 \mathrm{~min} ; \tau_{\text {minor }}=11.4 \mathrm{~min}$ $[\alpha]_{\mathrm{D}}{ }^{29}=+35.9\left(c 0.08, \mathrm{CHCl}_{3}, 90 \%\right.$ ee $)\left\{\right.$ lit., ${ }^{[28]}[\alpha]_{\mathrm{D}}{ }^{23}$ $-26.4\left(c 3.11, \mathrm{CHCl}_{3}\right)$ for $(S)-4 \mathrm{ma}, 86 \%$ ee $\}$.

(S)-2-Nitro-1-p-tolylethanol (4na) ${ }^{[35]}$ Following the general procedure, and purifying the aldehyde $2 \mathbf{n}$ by column chromatography (eluted with $\mathrm{CH}_{2} \mathrm{Cl}_{2}$ ), compound 4na was obtained after 6 days of reaction at $-24{ }^{\circ} \mathrm{C}$ as a dark brown oil in $20 \%$ yield. The ee of the product was determined to be $84 \%$ by HPLC using a Daicel Chiralpak IB column ( $n$-hexane $/ i$-PrOH $=95: 5$, flow rate $1 \mathrm{~mL} \mathrm{~min}{ }^{-1}$, $\lambda=220 \mathrm{~nm}): \tau_{\text {major }}=19.8 \mathrm{~min} ; \tau_{\text {minor }}=17.0 \mathrm{~min} .[\alpha]_{\mathrm{D}}{ }^{18}=$ +26.8 (c $0.25, \mathrm{CHCl}_{3}, 84 \%$ ee $)\left\{\right.$ lit., ${ }^{[35]}[\alpha]_{\mathrm{D}}{ }^{20}+34.1(\mathrm{c}=$ $\left.1.90, \mathrm{CHCl}_{3}\right)$ for $(S)-4$ na, $84 \%$ ee $\}$.

(R)-1-(Benzyloxy)-3-nitropropan-2-ol (40a) ${ }^{[36]}$ Following the general procedure, compound 4oa was isolated by flash chromatography after $92 \mathrm{~h}$ of reaction at $-24{ }^{\circ} \mathrm{C}$ as a dark brown oil in $66 \%$ yield. The ee of the product was determined to be $76 \%$ by HPLC using a Daicel Chiralpak IB column ( $n$-hexane $/ i$-PrOH $=95: 5$, flow rate $1 \mathrm{~mL} \mathrm{~min}^{-1}$, $\lambda=227.7 \mathrm{~nm}): \tau_{\text {major }}=22.6 \mathrm{~min}$; $\tau_{\text {minor }}=25.0 \mathrm{~min} .[\alpha]_{\mathrm{D}}{ }^{24}=$ +7.8 (c $0.25, \mathrm{CHCl}_{3}, 76 \%$ ee $)\left\{\right.$ lit., ${ }^{[37]}[\alpha]_{\mathrm{D}}+1.5$ (c 0.9 , $\mathrm{CH}_{2} \mathrm{Cl}_{2}$ ) for $(R)-40 a, 80 \%$ ee $\}$.

\section{(S)-2-Nitro-1-(perfluorophenyl)ethanol}

$(4 \mathrm{pa})^{[37]}$

Following the general procedure, compound $4 \mathbf{p a}$ was isolated by flash chromatography $\left(\mathrm{SiO}_{2}\right.$, using Hex:EtOAc 95:5 to Hex:EtOAc 9:1) after $120 \mathrm{~h}$ of reaction at $-24{ }^{\circ} \mathrm{C}$ as a yellow oil in $>95 \%$ yield. The ee of the product was determined to be $86 \%$ by HPLC using a Daicel Chiralpak 
IA column $\left(n\right.$-hexane $/ i$-PrOH $=95: 5$, flow rate $1 \mathrm{~mL} \min ^{-1}$, $\lambda=232.8 \mathrm{~nm}): \tau_{\text {major }}=10.9 \mathrm{~min} ; \tau_{\text {minor }}=12.4 \mathrm{~min} .[\alpha]_{\mathrm{D}}{ }^{28}=$ +2.8 (c $1.1, \mathrm{CHCl}_{3}, 86 \%$ ee) $\left\{\right.$ lit., ${ }^{[37]}[\alpha]_{\mathrm{D}}+8.9$ (c 0.8 , $\mathrm{CH}_{2} \mathrm{Cl}_{2}$ ) for $(S)-40 a, 90 \%$ ee $\}$.

\section{2-Nitro-1-(4-nitrophenyl)propan-1-ol \\ $(4 \mathbf{a b})^{[34,38]}$ Following the general procedure, compound $\mathbf{4 a b}$ was isolated by flash chromatography $\left(\mathrm{SiO}_{2}\right.$, using Hex:EtOAc 95:5 to Hex:EtOAc 9:1) after $88 \mathrm{~h}$ of reaction at $-24{ }^{\circ} \mathrm{C}$ as a dark green solid in $75 \%$ yield. ${ }^{[34,38]}$ The diastereomeric ratio (anti/syn, 1:1.3) was determined by ${ }^{1} \mathrm{H}$ NMR. The ee of the products was determined to be $72 \%$ (syn isomer) by HPLC using a Daicel Chiralpak IA column ( $n$-hexane/ $i$ -

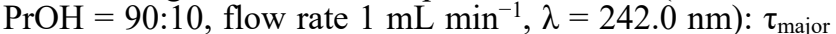 $=29.9 \mathrm{~min} ; \tau_{\mathrm{minor}}=25.9 \mathrm{~min}$; for the $\operatorname{syn}$ diastereoisomer.}

\section{2-Nitro-1-(3-nitrophenyl)propan-1-ol \\ $(4 \mathbf{b b})^{[34,38]}$ Following the general procedure, compound $4 \mathbf{b b}$ was isolated by flash chromatography $\left(\mathrm{SiO}_{2}\right.$, using Hex:EtOAc 95:5 to Hex:EtOAc 9:1) after $91 \mathrm{~h}$ of reaction at $-24{ }^{\circ} \mathrm{C}$ as a dark green solid in 74\% yield. The diastereomeric ratio (anti/syn, 1:1.4) was determined by ${ }^{1} \mathrm{H}$ NMR. ${ }^{[34,38]}$ The ee of the products was determined to be $87 \%$ (syn isomer) by HPLC using a Daicel Chiralpak IB column ( $n$-hexane/ $i$ - $\mathrm{PrOH}=95: 5$, flow rate $\left.1 \mathrm{~mL} \min ^{-1}, \lambda=238.4 \mathrm{~nm}\right): \tau_{\text {major }}$ $=35.6 \mathrm{~min} ; \tau_{\mathrm{minor}}=31.5 \mathrm{~min}$; for the $\operatorname{syn}$ diastereoisomer.}

\section{Acknowledgements}

We thank the Ministerio de Economia $y$ Competitividad (MINECO, Project CTQ2013-44367-C2-1-P), the University of Zaragoza (JIUZ-2014-CIE-07), the High Council of Scientific Investigation (CSIC) (PIE-201580I010) and Government of Aragon DGA (Research Group E-104) for financial support of our research. J.V.A.-R. thanks the DGA for a predoctoral contract.

\section{References}

[1] P. M. Pihko (Ed.), Hydrogen Bonding in Organic Synthesis; Wiley-VCH: Weinheim, 2009.

[2] F. Liu, Chirality 2013, 25, 675-683.

[3] For a review, see: a) F. Giacalone, M. Gruttadauria, P. Agrigento, R. Noto, Chem. Soc. Rev. 2012, 41, 24062447. For a recent example of low catalyst loading in an organocascade reaction, see also: b) C. C. J. Loh, P. Chauhan, D. Hack, C. Lehmann, D. Enders, Adv. Synth. Catal. 2014, 356, 3181-3186.

[4] L. Henry, C. R. Hebd. Séances Acad. Sci. 1895, 120, 1265-1268.

[5] F. A. Luzzio, Tetrahedron 2001, 57, 915-945.

[6] N. Ono (Ed.), The Nitro Group in Organic Synthesis; Wiley-VCH: New York, USA, 2001.

[7] S. C. Bergmeier, Tetrahedron 2000, 56, 2561-2576.

[8] J. Boruwa, N. Gogoi, P. P. Saikia, N. C. Barua, Tetrahedron: Asymmetry 2006, 17, 3315-3326.

[9] a) C. Palomo, M. Oiarbide, A. Mielgo, Angew. Chem. Int. Ed. 2004, 43, 5442-5444; b) C. Palomo, M. Oiarbide, A. Laso, Eur. J. Org. Chem. 2007, 25612576; c) Y. Alvarez-Casao, E. Marqués-López, R. P. Herrera, Symmetry 2011, 3, 220-245.
[10] R. Chinchilla, C. Nájera, P. Sánchez-Agulló, Tetrahedron: Asymmetry 1994, 5, 1393-1402.

[11] To the best of our knowledge, there are not any previous works regarding oxygen- $\pi$ and/or hydrogen- $\pi$ interactions in asymmetric catalysis. For the unique example of anion- $\pi$ catalysis, although non asymmetric, see: Y. Zhao, C. Beuchat, Y. Domoto, J. Gajewy, A. Wilson, J. Mareda, N. Sakai, S. Matile, J. Am. Chem. Soc. 2014, 136, 2101-2111.

[12] a) M. Nishio, Y. Umezawa, K. Honda, S. Tsuboyamad, H. Suezawa, CrystEngComm 2009, 11, 1757-1788. b) O. Takahashi, Y. Kohno, M. Nishio, Chem. Rev. 2010, 110, 6049-6076.

[13] a) H. Miyabe, Y. Takemoto, Bull. Chem. Soc. Jpn. 2008, 81, 785-795. b) S. J. Connon, Chem. Commun. 2008, 2499-2510. c) Y. Wei, M. Shi, Acc. Chem. Res. 2010, 43, 1005-1018. d) P. Chauhan, S. S. Chimni, $R S C A d v$. 2012, 2, 737-758. e) Y. Xiao, Z. Sun, H. Guo, O. Kwon, Beilstein J. Org. Chem. 2014, 10, 2089-2121. f) X. Fang, C.-J. Wang, Chem. Commun. 2015, 51, 1185-1197.

[14] For pivotal reviews concerning squaramides, see: a) J. Alemán, A. Parra, H. Jiang, K. A. Jørgensen, Chem. Eur. J. 2011, 17, 6890-6899. b) R. I. Storer, C. Aciro, L. H. Jones, Chem. Soc. Rev. 2011, 40, 2330-2346. c) F. R. Wurm, H.-A. Klok, Chem. Soc. Rev. 2013, 42, 82208236. d) J. V. Alegre-Requena, Synlett 2014, 25, 298299. e) P. Chauhan, S. Mahajan, U. Kaya, D. Hack, D. Enders, Adv. Synth. Catal. 2015, 357, 253-281.

[15] J. V. Alegre-Requena, E. Marqués-López, R. P. Herrera, RSC Adv. 2015, 5, 33450-33462.

[16] M. J. Frisch, G. W. Trucks, H. B. Schlegel, G. E. Scuseria, M. A. Robb, J. R. Cheeseman, G. Scalmani, V. Barone, B. Mennucci, G. A. Petersson, H. Nakatsuji, M. Caricato, X. Li, H. P. Hratchian, A. F. Izmaylov, J. Bloino, G. Zheng, J. L. Sonnenberg, M. Hada, M. Ehara, K. Toyota, R. Fukuda, J. Hasegawa, M. Ishida, T. Nakajima, Y. Honda, O. Kitao, H. Nakai, T. Vreven Jr., J. A. Montgomery, J. E. Peralta, F. Ogliaro, M. Bearpark, J. J. Heyd, E. Brothers, K. N. Kudin, V. N. Staroverov, R. Kobayashi, J. Normand, K. Raghavachari, A. Rendell, J. C. Burant, S. S. Iyengar, J. Tomasi, M. Cossi, N. Rega, N. J. Millam, M. Klene, J. E. Knox, J. B. Cross, V. Bakken, C. Adamo, J. Jaramillo, R. Gomperts, R. E. Stratmann, O. Yazyev, A. J. Austin, R. Cammi, C. Pomelli, J. W. Ochterski, R. L. Martin, K. Morokuma, V. G. Zakrzewski, G. A. Voth, P. Salvador, J. J. Dannenberg, S. Dapprich, A. D. Daniels, Ö. Farkas, J. B. Foresman, J. V. Ortiz, J. Cioslowski and D. J. Fox, All calculations were carried out with the Gaussian 09 suite of programs: Gaussian 09, Revision A.1, Gaussian, Inc., Wallingford, CT, 2009.

[17] E. R. Johnson, S. Keinan, P. Mori-Sánchez, J. Contreras-García, A. J. Cohen, W. Yang, J. Am. Chem. Soc. 2010, 132, 6498-6506.

[18] T. Lu, F. Chen, J. Comp. Chem. 2012, 33, 580-592. 
[19] W. Humphrey, A. Dalke, K. Schulten, J. Mol. Graphics 1996, 14, 33-38.

[20] H. Konishi, T. Y. Lam, J. P. Malerich, V. H. Rawal, Org. Lett. 2010, 12, 2028-2031.

[21] E. Marqués-López, J. V. Alegre-Requena, R. P. Herrera, European Pat. EP14382260.9 filed Jul. 07, 2014; b) J. V. Alegre-Requena, E. Marqués-López, R. P. Herrera, RSC Adv. 2015, 5, 33450-33462.

[22] W. Yang, D.-M. Du, Org. Lett. 2010, 12, 5450-5453.

[23] J. P. Malerich, K. Hagihara, V. H. Rawal, J. Am. Chem. Soc. 2008, 130, 14416-14417.

[24] H. Jiang, M. W. Paixão, D. Monge, K. A. Jørgensen, J. Am. Chem. Soc. 2010, 132, 2775-2783.

[25] M. Steurer, C. Bolm, J. Org. Chem. 2010, 75, 33013310 .

[26] S. Kitagaki, T. Ueda, C. Mukai, Chem. Commun. 2013, 49, 4030-4032.

[27] O. Soltani, M. A. Ariger, H. Vázquez-Villa, E. M. Carreira, Org. Lett. 2010, 12, 2893-2895.

[28] A. Bulut, A. Aslan, Ö. Dogan, J. Org. Chem. 2008, 73, 7373-7375.

[29] C. V.-L. Bray, F. Jiang, X.-F. Wu, J.-B. Sortais, C. Darcel, Tetrahedron Lett. 2010, 51, 4555-4557.
[30] E. C. Constable, G. Zhang, C. E. Housecroft, M. Neuburger, S. Schaffner, W.-D. Woggon, J. A. Zampese, New J. Chem. 2009, 33, 2166-2173.

[31] D. A. Evans, D. Seidel, M. Rueping, H. W. Lam, J. T. Shaw, C. W. Downey, J. Am. Chem. Soc. 2003, 125, 12692-12693.

[32] K. Kanagaraj, P. Sureh, K. Pitchumani, Org. Lett. 2010, 12, 4070-4073.

[33] T. Marcelli, R. N. S. van der Haas, J. H. van Maarseveen, H. Hiemstra, Angew. Chem. Int. Ed. 2006, 45, 929-931.

[34] K. Kanagaraj, P. Suresh, K. Pitchumani, Org. Lett. 2010, 12, 4070-4073.

[35] B. Zheng, M. Wang, Z. Li, Q. Bian, J. Mao, S. Li, S. Liu, M. Wang, J. Zhong, H. Guo, Tetrahedron: Asymmetry 2011, 22, 1156-1160.

[36] J. C. Borah, S. Gogoi, J. Boruwa, N. C. Barua, Synth. Commun. 2005, 35, 873-878.

[37] M. Bandini, F. Piccinelli, S. Tommasi, A. UmaniRonchi, C. Ventrici, Chem. Commun. 2007, 616-618.

[38] R. Boobalan, G.-H. Lee, C. Chen, Adv. Synth. Catal. 2012, 354, 2511-2520. 